\title{
Enhancement of the direct power control applied to DFIG-WECS
}

\author{
Hala Alami Aroussi ${ }^{1}$, EIMostafa Ziani ${ }^{2}$, Manale Bouderbala ${ }^{3}$, Badre Bossoufi ${ }^{4}$ \\ 1,2 Laboratory of Electrical and Maintenance Engineering (LGEM), Mohamed Premier University, Oujda, Morocco \\ ${ }^{3,4}$ LISTA Laboratory, Faculty of Sciences Dhar El Mahraz, Sidi Mohammed Ben Abdellah University, Fez, Morocco
}

\begin{tabular}{|c|c|}
\hline Article Info & ABSTRACT \\
\hline Article history: & \multirow{10}{*}{$\begin{array}{l}\text { This work is dedicated to the study of an improved direct control of powers } \\
\text { of the doubly fed induction generator (DFIG) incorporated in a wind energy } \\
\text { conversion system 'WECS'. The control method adopts direct power control } \\
\text { 'DPC' because of its various advantages like the ease of implementation } \\
\text { which allows decoupled regulation for active and reactive powers, as well as } \\
\text { a good performance at transient and steady state without PI regulators and } \\
\text { rotating coordinate transformations. To do this, the modeling of the turbine } \\
\text { and generator is performed. Therefore, the Maximum Power Point Tracking } \\
\text { (MPPT) technology is implemented to extract optimal power at variable } \\
\text { wind speed conditions. Subsequently, an explanation of the said command is } \\
\text { spread out as well as the principle of adjusting the active and reactive power } \\
\text { according to the desired speed. Then, the estimation method of these two } \\
\text { control variables will be presented as well as the adopted switching table of } \\
\text { the hysteresis controller model used based on the model of the multilevel } \\
\text { inverters. Finally, the robustness of the developed system will be analyzed } \\
\text { with validation in Matlab/Simulink environment to illustrate the performance } \\
\text { of this command. }\end{array}$} \\
\hline Received Oct 29,2018 & \\
\hline Revised Jul 20, 2019 & \\
\hline Accepted Aug 29, 2019 & \\
\hline Keywords: & \\
\hline DFIG & \\
\hline $\mathrm{DPC}$ & \\
\hline Hysteresis controllers & \\
\hline MPPT & \\
\hline WECS & \\
\hline
\end{tabular}

Copyright (c) 2020 Institute of Advanced Engineering and Science. All rights reserved.

\section{Corresponding Author:}

Hala Alami Aroussi,

Laboratory of Electrical and Maintenance Engineering (LGEM),

Ecole Supérieur de Technologie, Mohamed Premier University,

BP 473 Complexe universitaire Al Qods, Oujda 60000 Oujda, Morocco.

Email : h.alamiarroussi@ump.ac.ma, alami.aroussi.hala@gmail.com

\section{INTRODUCTION}

The production of electrical energy in the world generates various pollutions. Thus, thermal power stations (coal, oil) are responsible for atmospheric emissions linked to the combustion of fossil fuels. In contrast, nuclear power plants, whose development will increase following the oil crisis, have no adverse influence on air quality although they produce radioactive waste that causes storage problems, treatment or transport.

Today, the fear of being limited to ephemeral energies, the awareness of the negative impact of these on the environment, the craze for renewable energies and the opening of the market of the production of energy towards other alternatives are factors that give an important place to these energies (hydraulic, wind, solar, biomass, ...) in the production of electricity [1-3].

Among the most coveted renewable energies, we find the wind energy that interests more and more countries as it produces a clean and sustainable energy. We also notice that a large part of wind turbines installed today is equipped with a doubly fed induction generator (DFIG). The latter allows the production of electricity under variable speed, this makes it possible to better exploit turbine resources. These turbines are also equipped with variable blade pitch angle in order to be adapted to different wind conditions. The turbine is controlled so as to permanently maximize the power produced independently of the variation of the wind profile [4]. 
The main objective of this work is to study the direct power control (active and reactive) applied to a DFIG in a wind energy conversion system (WECS) as shown in Figure 1. The common goal of this control is to ensure the sampling of sinusoidal currents while guaranteeing a unit power factor with a decoupled control of the active and reactive powers.

In this perspective, a complete modeling of the architecture is proposed in order to elaborate the DPC control law [5-7]. The whole of the system is implemented under the Matlab/Simulink environment and simulation results are exposed and analyzed in order to prove the efficiency of the control.

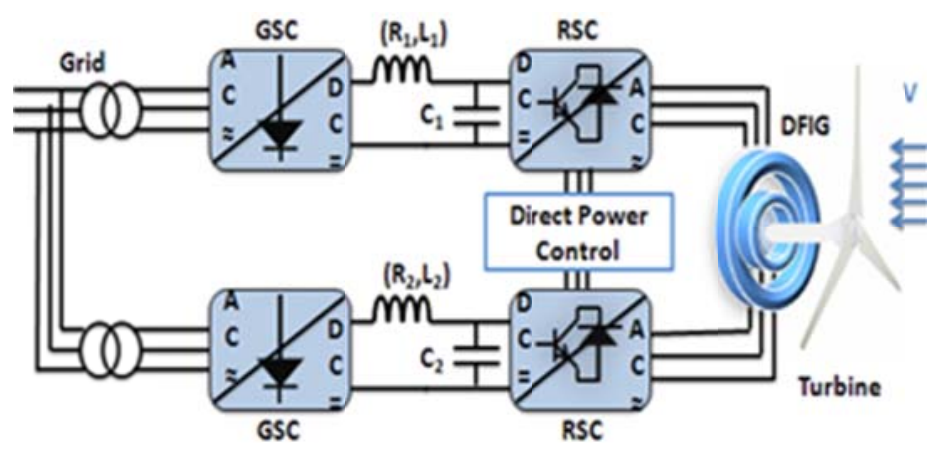

Figure 1. Synopsis of the direct power control of the DFIG-WECS

\section{TURBINE MODEL}

A theoretically undisturbed wind crossing a surface A without a decrease in speed $\mathrm{v}$ would give a theoretical power of the wind or wind power corresponding to the following expression:

$$
\mathrm{P}_{\text {theor }}=\frac{1}{2} \cdot \rho \cdot \mathrm{A} \cdot \mathrm{v}^{3}
$$

The aerodynamic power appearing at the rotor of the turbine is determined analytically by the following formula:

$$
P_{\text {aeor }}=\frac{1}{2} \cdot \rho \cdot A \cdot C_{p}(\lambda, \beta) \cdot v^{3}
$$

The power coefficient $C_{p}(\lambda, \beta)$ represents the aerodynamic efficiency of the turbine. It depends on the speed ratio $\lambda$ and the pitch angle of the blade $\beta$. The speed ratio is defined as the ratio of the linear speed of the blades and the wind speed:

$$
\lambda=\frac{\Omega_{\mathrm{t}} \times \mathrm{R}}{\mathrm{v}}
$$

Numerical approximations have been developed in the literature to model the coefficient $\mathrm{C}_{\mathrm{p}}$ and different expressions have been proposed $[4,8]$.

In the context of this work, we will use an approximate expression of the power coefficient as a function of the speed $\lambda$ and the angle $\beta$ as follows:

$$
c_{p}(\lambda, \beta)=c_{1}\left(c_{2} \cdot \frac{1}{\Lambda}-c_{3} \cdot \beta-c_{4}\right) \cdot e^{-c_{5} \frac{1}{\Lambda}}+c_{6} \cdot \lambda
$$

With : $\quad c 1=0.5872, \mathrm{c} 2=116, \mathrm{c} 3=0.4, \mathrm{c} 4=5, \mathrm{c} 5=21, \mathrm{c} 6=0.0085$.

and : $\quad \frac{1}{\Lambda}=\frac{1}{\lambda+0.08 . \beta}-\frac{0.035}{1+\beta^{3}}$

Figure 2 shows the simulation results under MATLAB/SIMULINK of the evolution of the coefficient $C_{p}$ as a function of the speed ratio $\lambda$ for a few pitch angles $\beta$. We note that this coefficient passes through a maximum $\left(C_{p_{-} \text {max }}=0.48\right)$ for $\beta=0$ and a particular value of the speed ratio that we will designate by $\lambda_{\text {opt }}\left(\right.$ where $\left.\lambda_{\text {opt }}=8\right)$. 


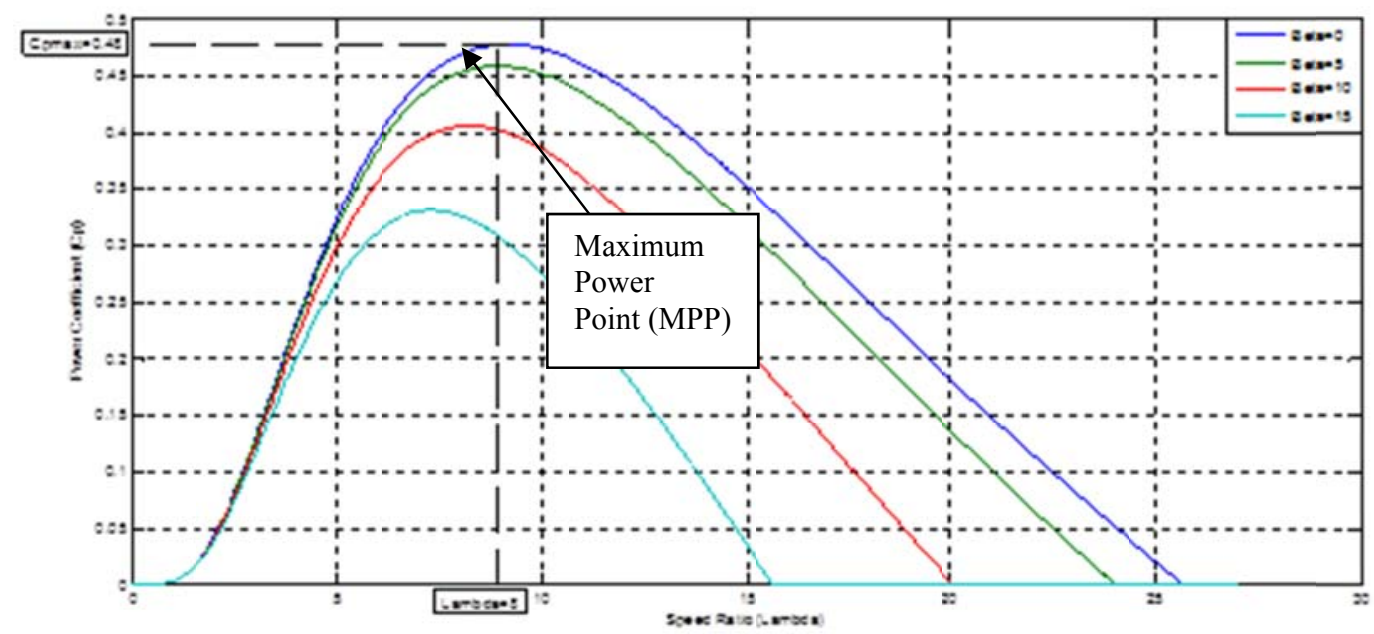

Figure 2. Power coefficient as a function of $\lambda$ and $\beta$

\section{MAXIMUM POWER POINT TRACKING STRATEGY}

Wind turbines, used for the production of electricity, must allow the production maximum of power by exploiting the energy available in the wind. This is why many wind turbine control systems, acting on the mechanical or electrical part, are developed to maximize the energy conversion. This is called Maximum Power Point Tracking (MPPT). These systems use different means to obtain this maximum power point. It is possible to change the pitch angle of the blades, or the speed of rotation of the propeller or even play on the control of the generator. The search for the maximum is done permanently and the wind turbine therefore adapts itself to each variation of wind to be in a configuration of maximum extraction of power. Such systems also introduce safety devices that allow for example to limit the power produced when the wind becomes too strong and may damage the wind turbine.

In this context, several types of MPPT algorithms exist. They can be divided in three groups: TSR (Tip Speed Ratio) control, Power control and Hill Climbing [9]. In this work, we focus on the TSR control because of its simplicity and accuracy. This technique regulates the rotational speed of the generator to maintain $\lambda$ at an optimal value so that the power extracted is maximal.

\section{DOUBLY FED INDUCTION GENERATOR MODEL}

In the literature, we find that the DFIG model in the reference dq related to the rotating flux is summarized in four types of equations: electrical, magnetic, electromagnetic and mechanical [10-14].

\subsection{Electrical equations}

$$
\left\{\begin{array}{l}
\mathrm{V}_{\mathrm{sd}}=\mathrm{R}_{\mathrm{s}} \mathrm{i}_{\mathrm{sd}}+\frac{\mathrm{d} \psi_{\mathrm{sd}}}{\mathrm{dt}}-\omega_{\mathrm{s}} \psi_{\mathrm{sq}} \\
\mathrm{V}_{\mathrm{sq}}=\mathrm{R}_{\mathrm{s}} \mathrm{i}_{\mathrm{sq}}+\frac{\mathrm{d} \psi_{\mathrm{sq}}}{\mathrm{dt}}+\omega_{\mathrm{s}} \psi_{\mathrm{sd}} \\
\mathrm{V}_{\mathrm{rd}}=\mathrm{R}_{\mathrm{r}} \mathrm{i}_{\mathrm{rd}}+\frac{\mathrm{d} \Psi_{\mathrm{rd}}}{\mathrm{dt}}-\left(\omega_{\mathrm{s}}-\omega_{\mathrm{r}}\right) \psi_{\mathrm{rq}} \\
\mathrm{V}_{\mathrm{rq}}=\mathrm{R}_{\mathrm{r}} \mathrm{i}_{\mathrm{rq}}+\frac{\mathrm{d} \Psi_{\mathrm{rq}}}{\mathrm{dt}}+\left(\omega_{\mathrm{s}}-\omega_{\mathrm{r}}\right) \psi_{\mathrm{rd}}
\end{array}\right.
$$

\subsection{Flux equations}

The stator and rotor flux are connected to currents by the following relations:

$$
\left\{\begin{array}{l}
\psi_{\mathrm{sd}}=\mathrm{L}_{\mathrm{s}} \mathrm{i}_{\mathrm{sd}}+\mathrm{Mi}_{\mathrm{rd}} \\
\psi_{\mathrm{sq}}=\mathrm{L}_{\mathrm{s}} \mathrm{i}_{\mathrm{sq}}+\mathrm{Mi}_{\mathrm{rq}} \\
\psi_{\mathrm{rd}}=\mathrm{L}_{\mathrm{r}} \mathrm{i}_{\mathrm{rd}}+\mathrm{Mi}_{\mathrm{sd}} \\
\psi_{\mathrm{rq}}=\mathrm{L}_{\mathrm{r}} \mathrm{i}_{\mathrm{rq}}+M \mathrm{Mi}_{\mathrm{sq}}
\end{array}\right.
$$




\subsection{Electromagnetic torque} is given by

The expression of the electromagnetic torque as a function of the stator flux and rotor current

$$
\mathrm{T}_{\mathrm{em}}=\frac{\mathrm{pM}}{\mathrm{L}_{\mathrm{s}}}\left(\mathrm{i}_{\mathrm{rd}} \psi_{\mathrm{sq}}-\mathrm{i}_{\mathrm{rq}} \psi_{\mathrm{sd}}\right)
$$

\subsection{Mechanical equation}

The evolution of the mechanical speed from the total mechanical torque $\left(\mathrm{T}_{\mathrm{mec}}\right)$ is determined by the fundamental equation of dynamics:

$$
\mathrm{J} \frac{\mathrm{d} \Omega_{\mathrm{mec}}}{\mathrm{dt}}=\mathrm{T}_{\text {mec }}=\mathrm{T}_{\text {aero }}-\mathrm{T}_{\mathrm{em}}-\mathrm{f} \Omega_{\mathrm{mec}}
$$

\section{DIRECT POWER CONTROL APPLIED TO THE DFIG}

\subsection{Principle of the direct power of control}

The basic principle of direct power control (DPC) was proposed by Noguchi [15], it is based initially on the direct control of torque (DTC), intended for the control of the electric motors [16-20]. In the case of DPC, active and reactive powers replace torque electromagnetic and the amplitude of the stator flux of the DTC. This non-linear control strategy is defined as a technique of direct control because it chooses the appropriate voltage vector of the converter without any modulation technique. The basic concept is to select the appropriate switching states from a switch table based on errors, which are limited by a band hysteresis, present in the active and reactive powers.

Instant active and reactive powers are calculated from the expressions below:

$$
\begin{aligned}
& \mathrm{P}_{\mathrm{s}}=-\frac{3}{2} \frac{\mathrm{L}_{\mathrm{m}}}{\sigma \mathrm{L}_{\mathrm{s}} \mathrm{L}_{\mathrm{r}}} \omega_{\mathrm{s}}\left|\Psi_{\mathrm{s}}\right|\left|\psi_{\mathrm{r}}\right| \sin \delta \\
& \mathrm{Q}_{\mathrm{s}}=\frac{3}{2} \frac{\omega_{\mathrm{s}}}{\sigma \mathrm{L}_{\mathrm{s}}}\left|\Psi_{\mathrm{s}}\right|\left(\frac{\mathrm{L}_{\mathrm{m}}}{\mathrm{L}_{\mathrm{r}}}\left|\psi_{\mathrm{r}}\right| \cos \delta-\left|\psi_{\mathrm{s}}\right|\right)
\end{aligned}
$$

with : $\delta$ The angle between the stator's flux and the rotor's flux vectors.

$$
\sigma=1-\frac{\mathrm{M}^{2}}{\mathrm{~L}_{\mathrm{s}} \mathrm{L}_{\mathrm{r}}}: \text { Coefficient of dispersion. }
$$

The reference active power is calculated from the output of the DC bus voltage regulator $U_{D C}[21]$. The reference of the reactive power is maintained at zero in order to ensure a unit power factor. Then, the powers are compared and the errors obtained are applied to regulators of hysteresis.

\subsection{Hysteresis controller}

The main idea of direct power control is to maintain the instant active and reactive powers in a desired band. This control is based on two hysteresis comparators which use as input the error signals between the reference values and estimates of the active and reactive powers. These two controllers are responsible for deciding how much a new switch and/or output voltage vector of the inverter is applied. If the error of the power ( $e P s$ or $e Q s$ ) is increasing and reaches the higher level, the hysteresis controller changes its output to ' 1 '.

\subsection{Vector selection}

The influence of each output vector on the active and reactive powers is very dependent on the actual position of the vector of the source voltage Thus, in addition to the signals of the two hysteresis controllers, the switching table operates according to the position of the vector of the source voltage, which turns to the pulsation $\left(\boldsymbol{\omega}_{m}\right)$, in the complex plan. However, instead of introducing to the switching table the exact position of the vector of the voltage, the sector selection block informs us in which domain the current vector of the source voltage is located $[22,23]$. Therefore, we propose to use a modified DPC which, unlike the conventional DPC, can produce twenty seven voltage vectors instead of the eight vectors. In other words, we will decompose twelve sectors instead of six in order to increase the accuracy and also to avoid the problems encountered in boundaries of each control vector. With this in mind, we used a five-stage hysteresis corrector for the reactive power and a three-level corrector for the active power. 


\subsection{Switching table}

The switching table is the paramount part in direct power control. It selects the appropriate voltage vector of the inverter in order to orient the instantaneous active and reactive powers in their desired value, also based on the position of the source voltage vector and the errors of the active and reactive powers [24]. In this work, we adopted a modified switching table compared to that developed by Noguchi to ensure optimal minimization in error power as shown in Table 1.

Table 1. Switching table for 3-levels and 5-levels inverter

\begin{tabular}{|c|c|c|c|c|c|c|c|c|c|c|c|c|c|}
\hline Secto & umb & 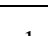 & 0 & ( & 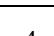 & 5 & 6 & 7 & & - & 1 & & \\
\hline$e P_{S}$ & $e Q_{s}$ & 1 & 2 & 3 & 4 & 5 & 6 & 7 & 8 & 9 & 10 & 11 & 12 \\
\hline 1 & 2 & $\overline{\overline{V_{21}}}$ & $\overline{\overline{V_{16}}}$ & $\overline{\overline{V_{22}}}$ & $\overline{\overline{V_{17}}}$ & $\overline{\overline{V_{23}}}$ & $\overline{\overline{V_{18}}}$ & $\overline{\overline{V_{24}}}$ & $\overline{\overline{V_{19}}}$ & $\overline{\overline{V_{25}}}$ & $\overline{\overline{V_{20}}}$ & $\overline{\overline{V_{26}}}$ & $\overline{\overline{V_{15}}}$ \\
\hline & 1 & $\frac{21}{V_{21}}$ & $\overline{V_{2}}$ & $\frac{\overline{2}}{V_{22}}$ & $\overline{V_{3}}$ & $\frac{r_{23}}{V_{23}}$ & $\frac{18}{V_{4}}$ & $\frac{r_{24}}{V_{24}}$ & $\overline{V_{5}}$ & $\frac{25}{V_{25}}$ & $\overline{V_{6}}$ & $\frac{26}{V_{26}}$ & $\overline{V_{1}}$ \\
\hline & 0 & $\bar{V}_{0}$ & $\overline{V_{7}}$ & $\frac{2}{V_{14}}$ & $\overline{V_{0}}$ & $\bar{V}_{7}$ & $\overline{V_{14}}$ & $\bar{V}_{0}$ & $\overline{V_{7}}$ & $\frac{L_{v}}{V_{14}}$ & $\overline{V_{0}}$ & $\bar{V}_{7}$ & $\overline{V_{14}}$ \\
\hline & -1 & $\overline{V_{26}}$ & $\overline{\overline{V_{1}}}$ & $\overline{V_{21}}$ & $\overline{\overline{V_{2}}}$ & $\overline{V_{22}}$ & $\overline{V_{3}}$ & $\overline{V_{23}}$ & $\overline{\bar{V}}_{4}$ & $\overline{V_{24}}$ & $\overline{V_{5}}$ & $\overline{V_{25}}$ & $\bar{V}_{6}$ \\
\hline & -2 & $\overline{V_{26}}$ & $\overline{V_{15}}$ & $\overline{V_{21}}$ & $\overline{V_{16}}$ & $\overline{V_{22}}$ & $\overline{V_{17}}$ & $\overline{V_{23}}$ & $\overline{V_{18}}$ & $\overline{V_{24}}$ & $\overline{V_{19}}$ & $\overline{V_{25}}$ & $\overline{V_{20}}$ \\
\hline 0 & 2 & $\frac{20}{V_{22}}$ & $\frac{1}{V_{17}}$ & $\frac{21}{V_{23}}$ & $\frac{10}{V_{18}}$ & $\frac{L_{2}}{V_{24}}$ & $\frac{\bar{V}}{V_{19}}$ & $\frac{L_{5}}{V_{25}}$ & $\frac{10}{V_{20}}$ & $\frac{L_{46}}{V_{26}}$ & $\overline{V_{15}}$ & $\frac{b_{2}}{V_{21}}$ & $\frac{\bar{v}}{V_{16}}$ \\
\hline & 1 & $\overline{V_{22}}$ & $\overline{\bar{V}_{3}}$ & $\overline{V_{23}}$ & $\bar{V}_{4}$ & $\overline{V_{24}}$ & $\overline{V_{5}}$ & $\overline{V_{25}}$ & $\bar{V}_{6}$ & $\overline{V_{26}}$ & $\overline{V_{1}}$ & $\overline{V_{21}}$ & $\overline{V_{2}}$ \\
\hline & 0 & $\overline{V_{0}}$ & $\overline{V_{7}}$ & $\overline{V_{14}}$ & $\overline{V_{0}}$ & $\bar{V}_{7}$ & $\overline{V_{14}}$ & $\overline{V_{0}}$ & $\overline{V_{7}}$ & $\frac{20}{V_{14}}$ & $\overline{V_{0}}$ & $\bar{V}_{7}$ & $\frac{\bar{L}}{V_{14}}$ \\
\hline & -1 & $\overline{V_{25}}$ & $\overline{V_{6}}$ & $\overline{V_{26}}$ & $\overline{V_{1}}$ & $\overline{V_{21}}$ & $\overline{V_{2}}$ & $\overline{V_{22}}$ & $\overline{V_{3}}$ & $\overline{V_{23}}$ & $\overline{V_{4}}$ & $\overline{V_{24}}$ & $\bar{V}_{5}$ \\
\hline & -2 & $\overline{V_{25}}$ & $\overline{V_{20}}$ & $\overline{V_{26}}$ & $\overline{V_{15}}$ & $\overline{V_{21}}$ & $\overline{V_{16}}$ & $\overline{V_{22}}$ & $\overline{V_{17}}$ & $\overline{V_{23}}$ & $\overline{V_{18}}$ & $\overline{V_{24}}$ & $\overline{V_{19}}$ \\
\hline-1 & 2 & $\overline{V_{17}}$ & $\overline{V_{23}}$ & $\overline{V_{18}}$ & $\overline{V_{24}}$ & $\overline{V_{19}}$ & $\overline{V_{25}}$ & $\overline{V_{20}}$ & $\overline{V_{26}}$ & $\overline{V_{15}}$ & $\overline{V_{21}}$ & $\overline{V_{16}}$ & $\overline{V_{22}}$ \\
\hline & 1 & $\overline{\bar{V}_{3}}$ & $\frac{2 v}{V_{23}}$ & $\overline{\bar{V}}_{4}$ & $\overline{V_{24}}$ & $\overline{\bar{V}_{5}}$ & $\frac{\bar{V}}{V_{25}}$ & $\frac{\overline{V_{6}}}{\sigma}$ & $\frac{\bar{V}}{V_{26}}$ & $\overline{\bar{V}}_{1}$ & $\frac{2}{V_{21}}$ & $\bar{V}_{2}$ & $\frac{\bar{V}}{V_{22}}$ \\
\hline & 0 & $\bar{V}_{0}$ & $\bar{V}_{7}$ & $\overline{V_{14}}$ & $\overline{V_{0}}$ & $\overline{V_{7}}$ & $\frac{25}{V_{14}}$ & $\overline{V_{0}}$ & $\overline{V_{7}}$ & $\overline{V_{14}}$ & $\overline{V_{0}}$ & $\overline{V_{7}}$ & $\frac{24}{V_{14}}$ \\
\hline & -1 & $\overline{V_{5}}$ & $\overline{V_{25}}$ & $\bar{V}_{6}$ & $\overline{V_{26}}$ & $\overline{V_{1}}$ & $\frac{14}{V_{21}}$ & $\overline{V_{2}}$ & $\frac{1}{V_{22}}$ & $\overline{V_{3}}$ & $\overline{V_{23}}$ & $\overline{V_{4}}$ & $\frac{\overline{V_{24}}}{4}$ \\
\hline & & $\overline{V_{19}}$ & $\overline{V_{25}}$ & $\overline{V_{20}}$ & $\overline{V_{26}}$ & $\overline{V_{15}}$ & $\overline{V_{21}}$ & $\overline{V_{16}}$ & $\overline{V_{22}}$ & $\overline{V_{17}}$ & $\overline{V_{23}}$ & $\overline{V_{18}}$ & $\overline{V_{24}}$ \\
\hline & & & & & & & 01 & $; \bar{V}_{5}=$ & 0 & $\bar{V}_{6}=[1$ & $0,1]$ & $=[1,1$ & 1] ; \\
\hline & & & & & & & & & & & & & -1]; \\
\hline & 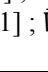 & 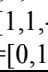 & & & & & & & & & & & -1]; \\
\hline
\end{tabular}

\section{APPLICATIONS AND RESULTS}

The Figure 3 shows the block diagram of the model used for the control of the doubly fed induction generator for a wind system in Matlab/Simulink environment [25]:

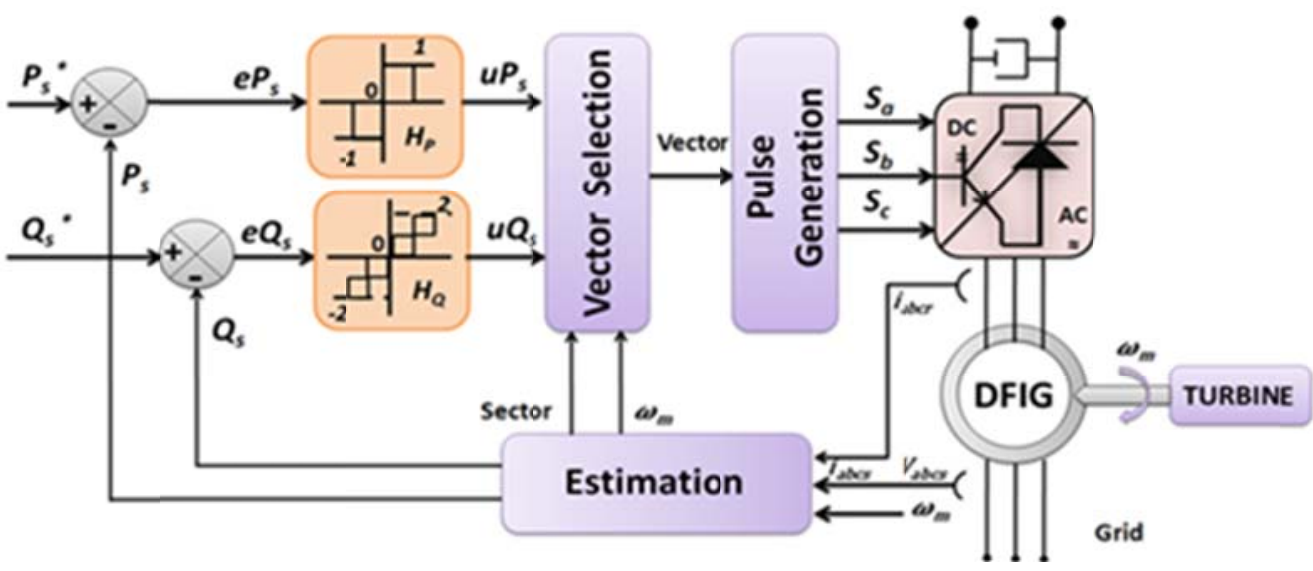

Figure 3. Direct power control (DPC) block diagram

\subsection{Setpoint tracking test}

The system is analysed during steady-state and transients conditions at variable wind speed (sub-synchronous, synchronous and super-synchronous). The different parameters of the doubly fed induction generator and the wind turbine are given respectively in Table 2 and Table 3 . The results of the simulation are shown in Figure 4. 
Table 2. Parameters of the doubly fed induction generator

\begin{tabular}{ll}
\hline \multicolumn{2}{c}{ DFIG Parameters } \\
\hline Nominal Power & $\mathrm{Pn}=1.5 \mathrm{KW}$ \\
Stator Voltage & $\mathrm{Vs}=220 / 380 \mathrm{~V}$ \\
Stator Frequency & $\mathrm{fs}=50 \mathrm{~Hz}$ \\
Stator Resistance & $\mathrm{Rs}=1.18 \Omega$ \\
Stator Inductance & $\mathrm{Ls}=0.4 \mathrm{H}$ \\
Rotor Resistance & $\mathrm{Rr}=1.66 \Omega$ \\
Rotor Inductance & $\mathrm{Lr}=0.18 \mathrm{H}$ \\
Mutual Inductance & $\mathrm{M}=0.17 \mathrm{H}$ \\
No. of Pair of Poles & $\mathrm{P}=2$ \\
\hline
\end{tabular}

Table 3. Parameters of the wind turbine

\begin{tabular}{ll}
\hline \multicolumn{2}{c}{ Turbine Parameters } \\
\hline Rated power & $1.5 \mathrm{KW}$ \\
Number of blades & 3 \\
Rotor Radius & $\mathrm{R}=1 \mathrm{~m}$ \\
Gearbox ratio & $\mathrm{G}=2$ \\
Moment of inertia & $\mathrm{J}=1000 \mathrm{Kg} \cdot \mathrm{m}^{2}$ \\
Viscous friction coefficient & $\mathrm{f}_{\mathrm{v}}=0.007 \mathrm{~N} \cdot \mathrm{m} \cdot \mathrm{s}^{-1}$ \\
\hline
\end{tabular}

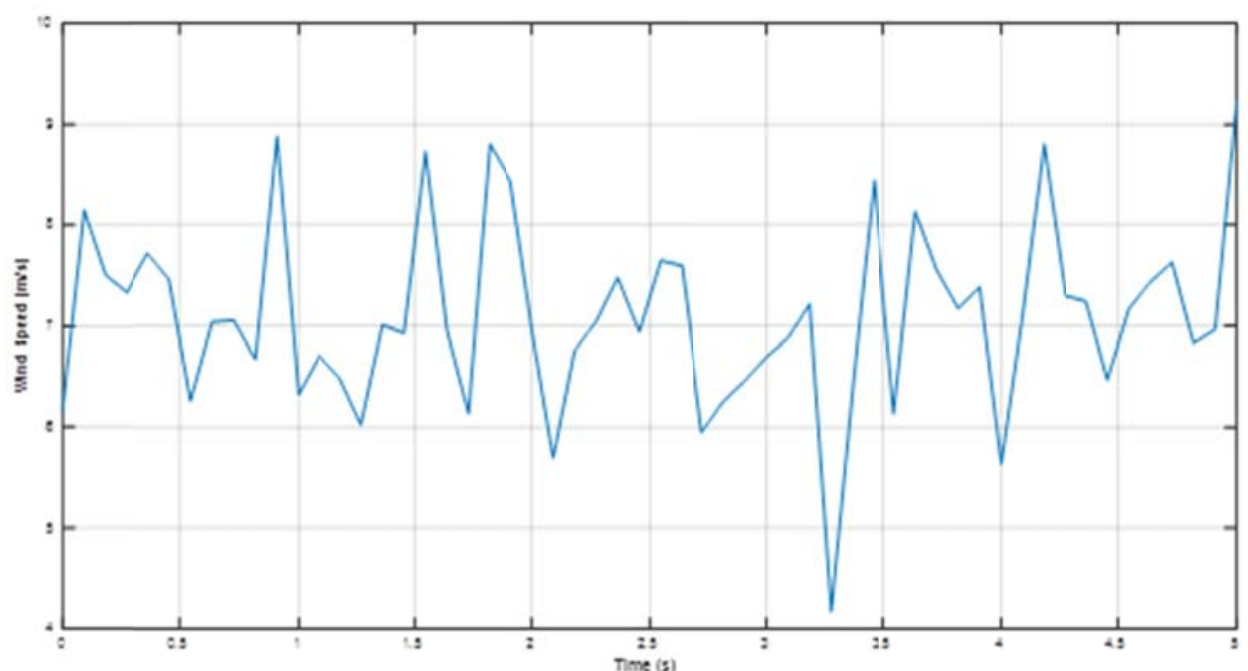

(a)

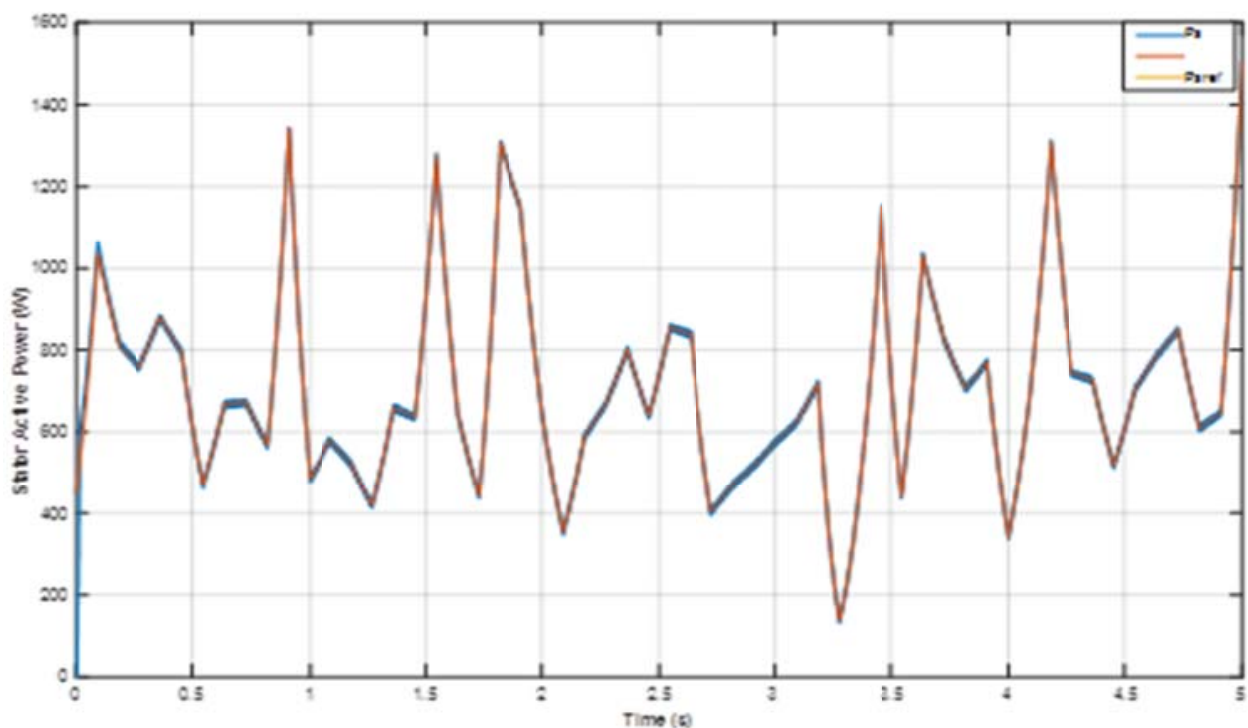

(b)

Figure 4. (a) Curves of: the wind speed, (b) the stator active power 


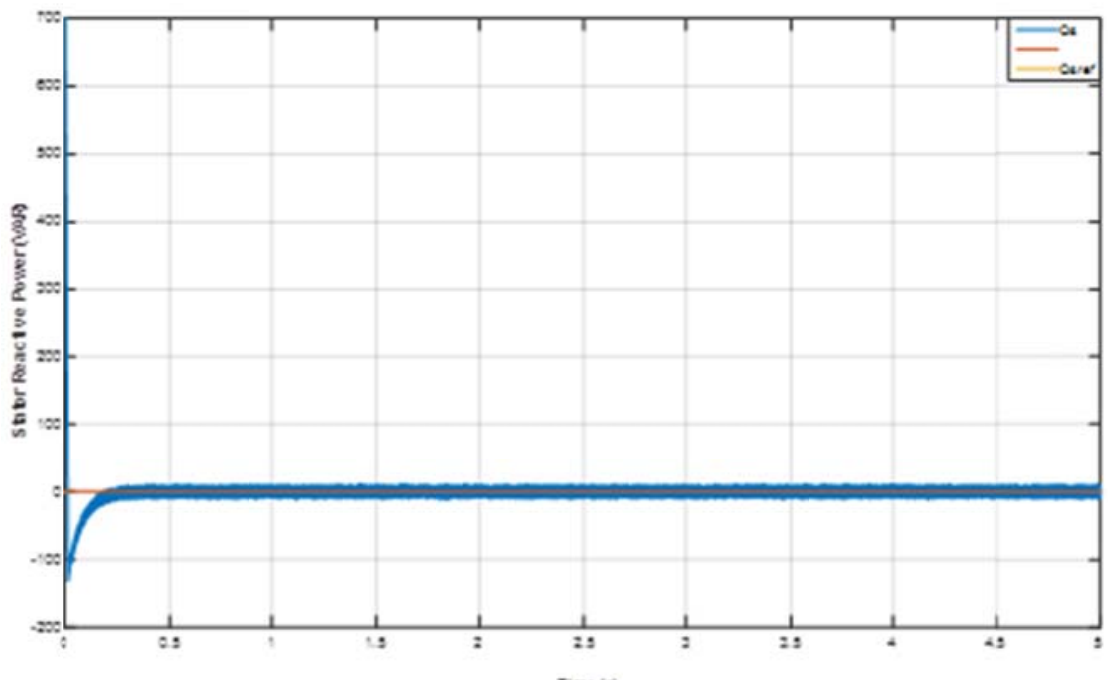

(c)

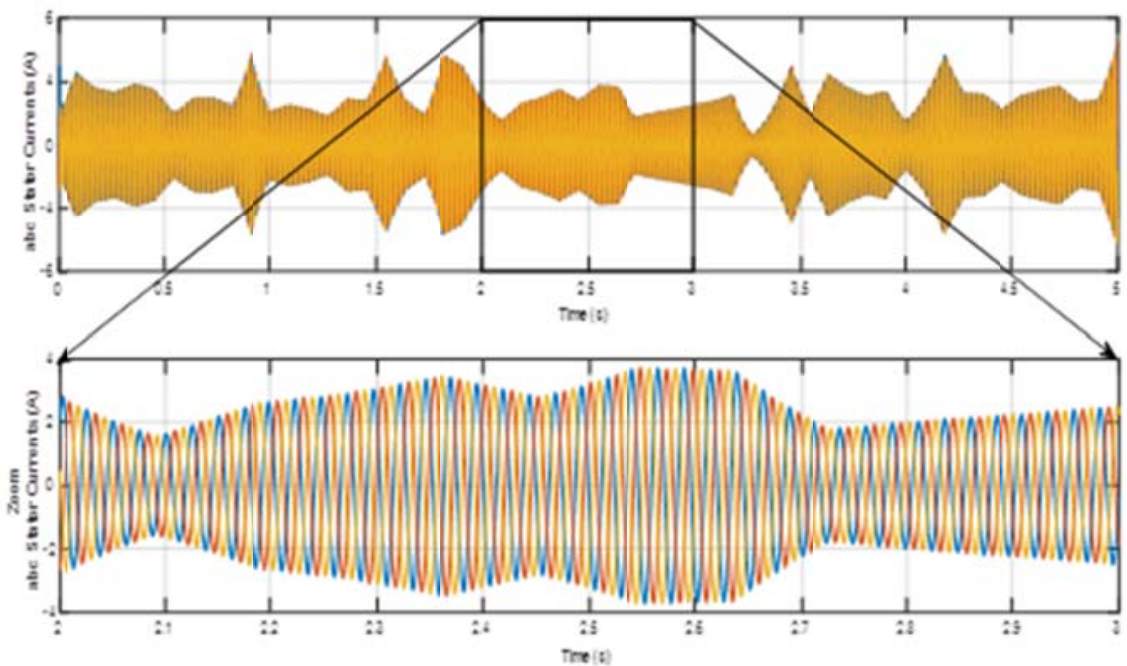

(d)

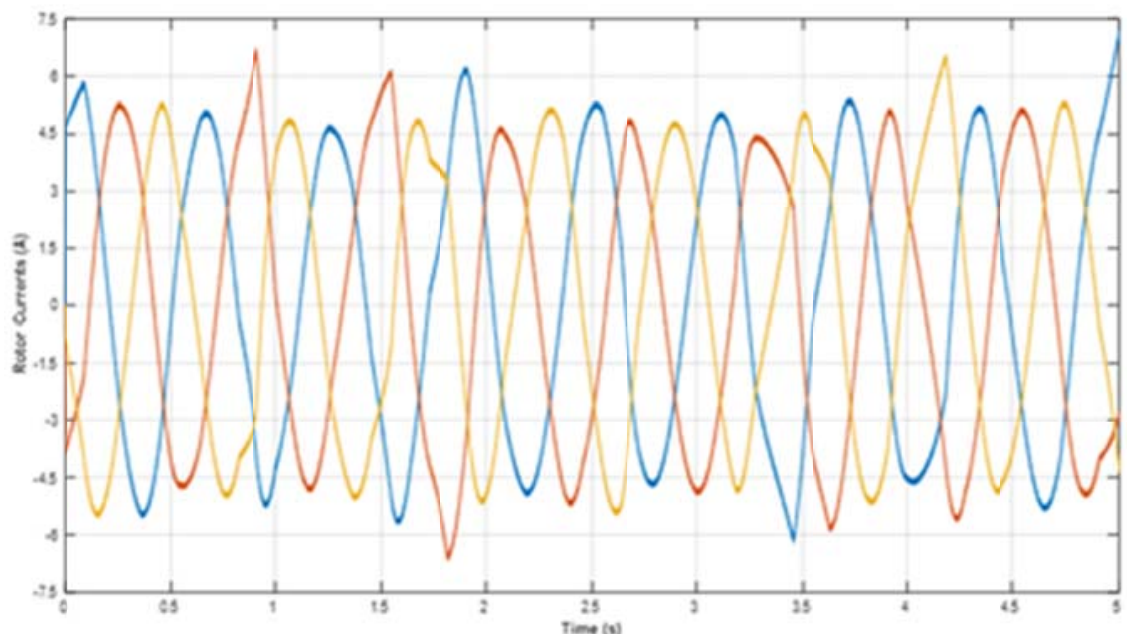

(e)

Figure 4. (c) the stator reactive power, (d) the currents of the stator, (e) the currents of the rotor 


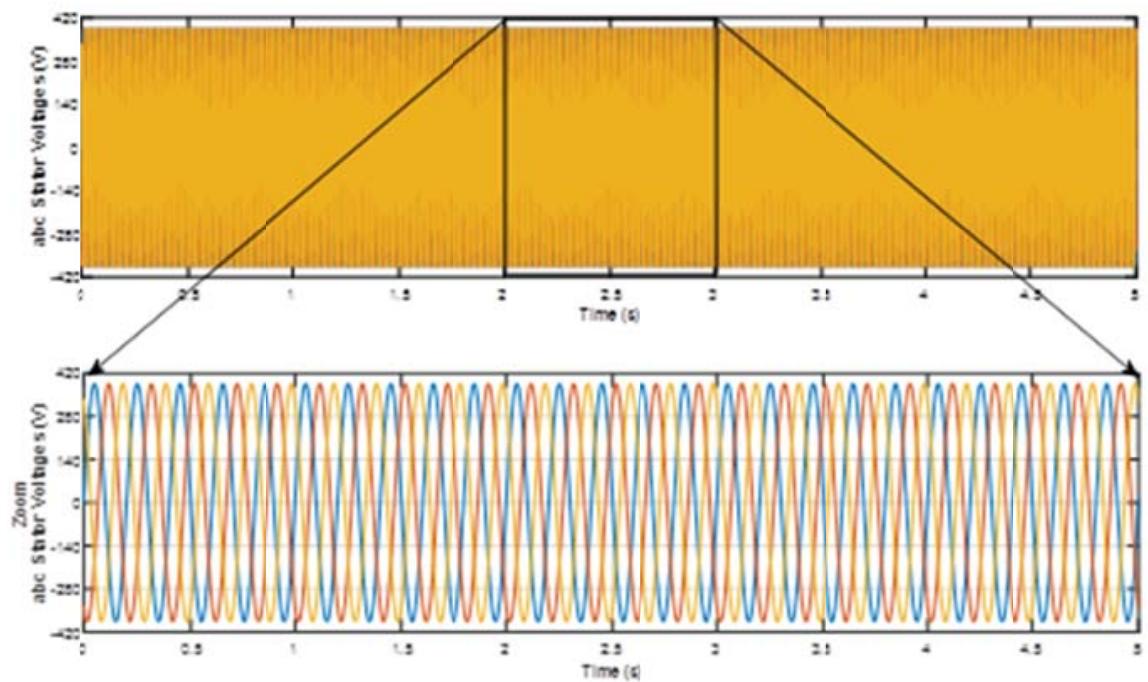

(f)

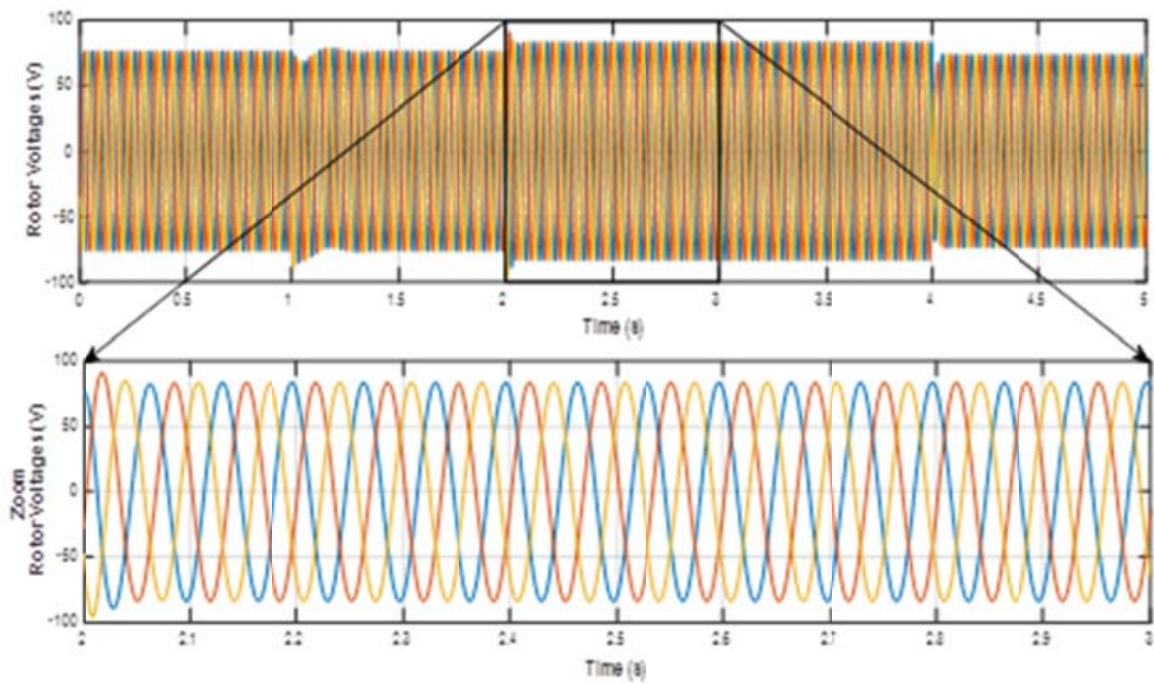

(g)

Figure 4. (f) the voltages of the stator, (g) the voltages of the rotor

\subsection{Robustness test}

The parameters of the DFIG are exposed to variations caused by various changes such as temperature increase, skin effect, etc. In this case, the proposed DPC must guarantee good results regardless of the parameter variations. So, the robustness of the command used (DPC) has been tested according to the following conditions:

a. Resistance $\mathrm{R}_{\mathrm{s}}$ multiplied by 2

b. Inductances $\mathrm{L}_{\mathrm{s}}$ and $\mathrm{L}_{\mathrm{r}}$ multiplied by 0.5 .

Figure 5 shows the simulation's results obtained. Comparing the results of the simulations illustrated in Figure 4 and Figure 5 we can ensure, even by changing the initial values of DFIG, that:

a. The stator active and reactive powers follow their references with fewer oscillations and disturbances due to hysteresis controller but the values of powers quickly regain their references.

b. The stator and rotor currents (respectively voltages) in the frame (a, b, c) have a sinusoidal shape.

From these results, we can conclude that the technique of DPC has a low response time in the transient regime, and fewer disturbance oscillations in the curves of the various curves that quickly regain their reference values. The robustness of this approach remains good for the wind energy conversion system. 


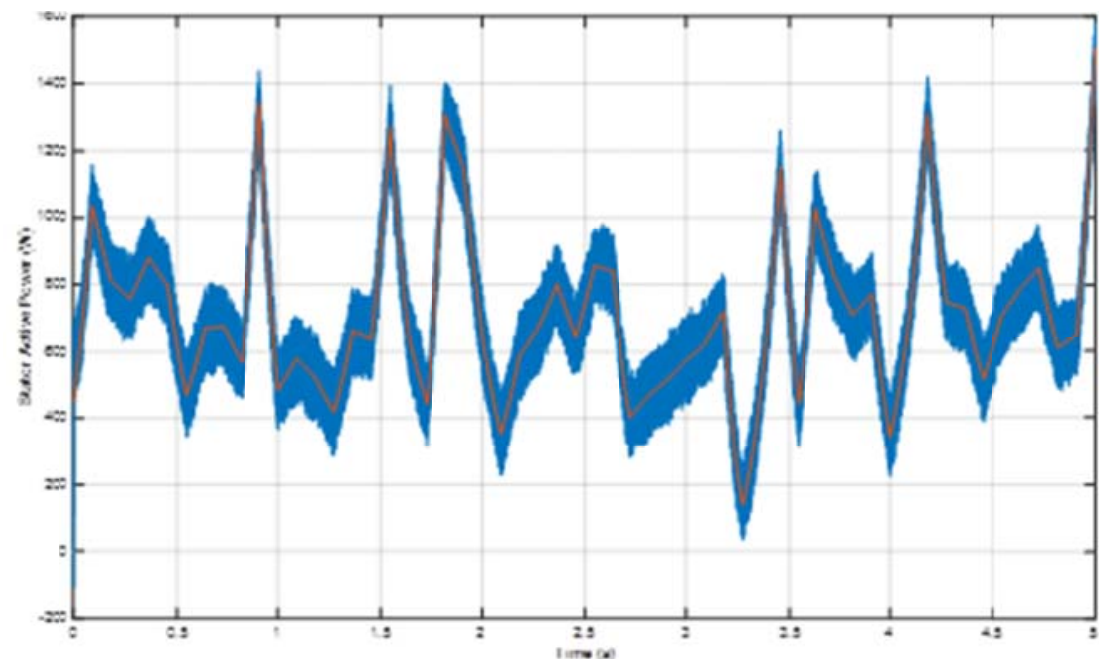

(a)

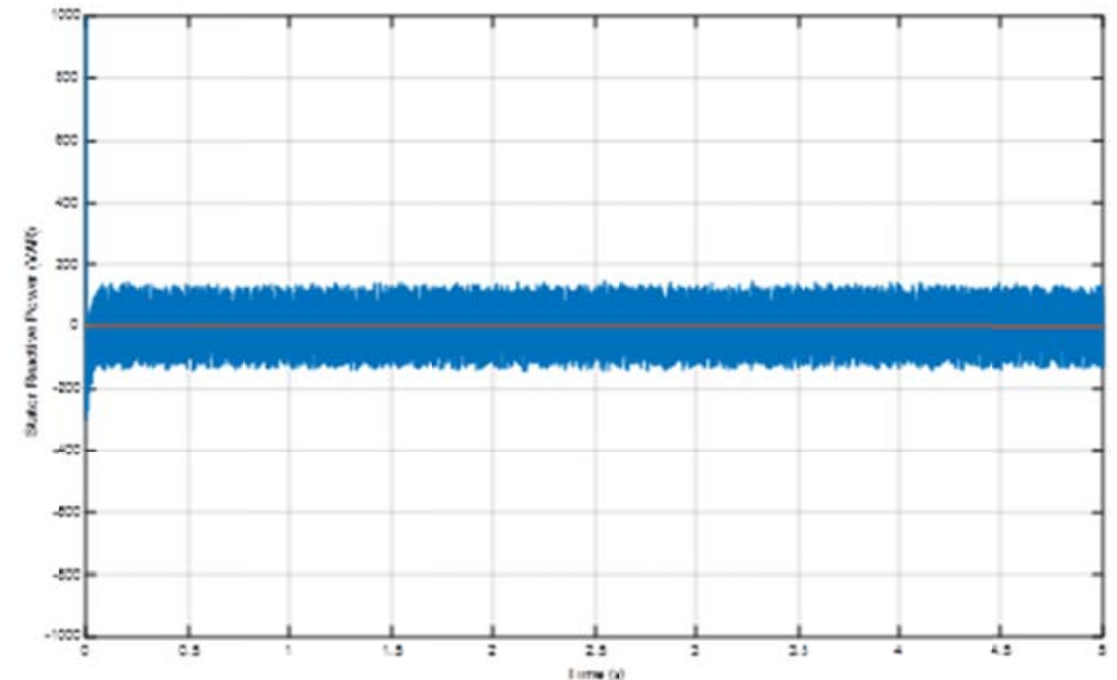

(b)

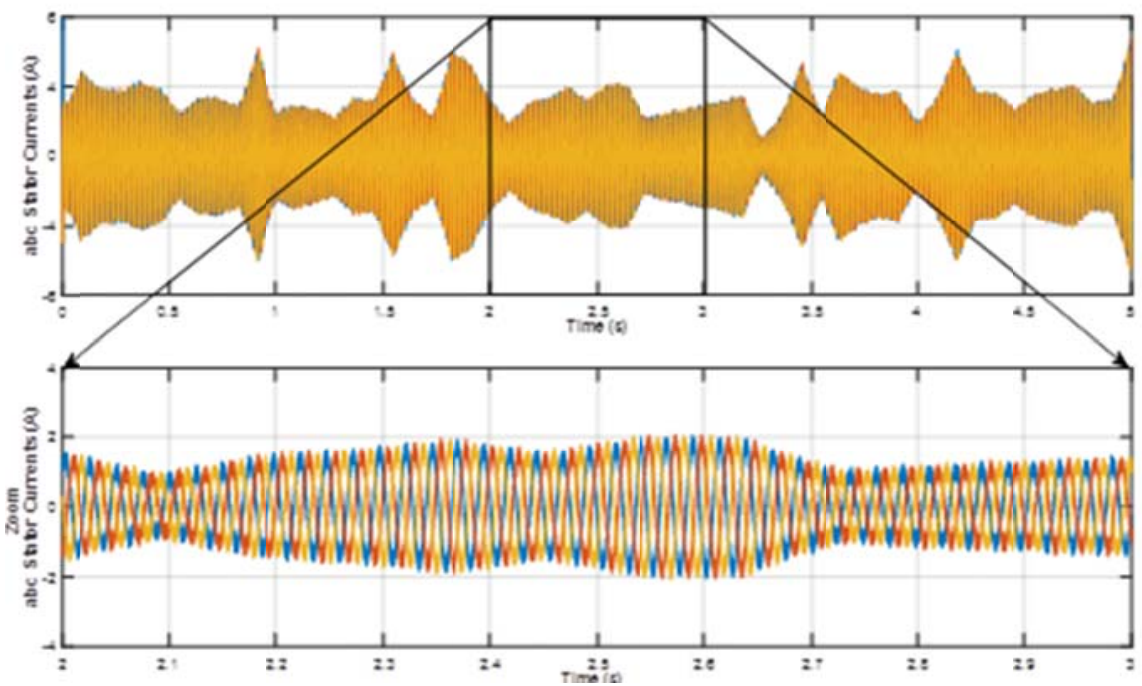

(c)

Figure 5. Curves of: (a) the stator active power, (b) the stator reactive power, (c) the currents of the stator 


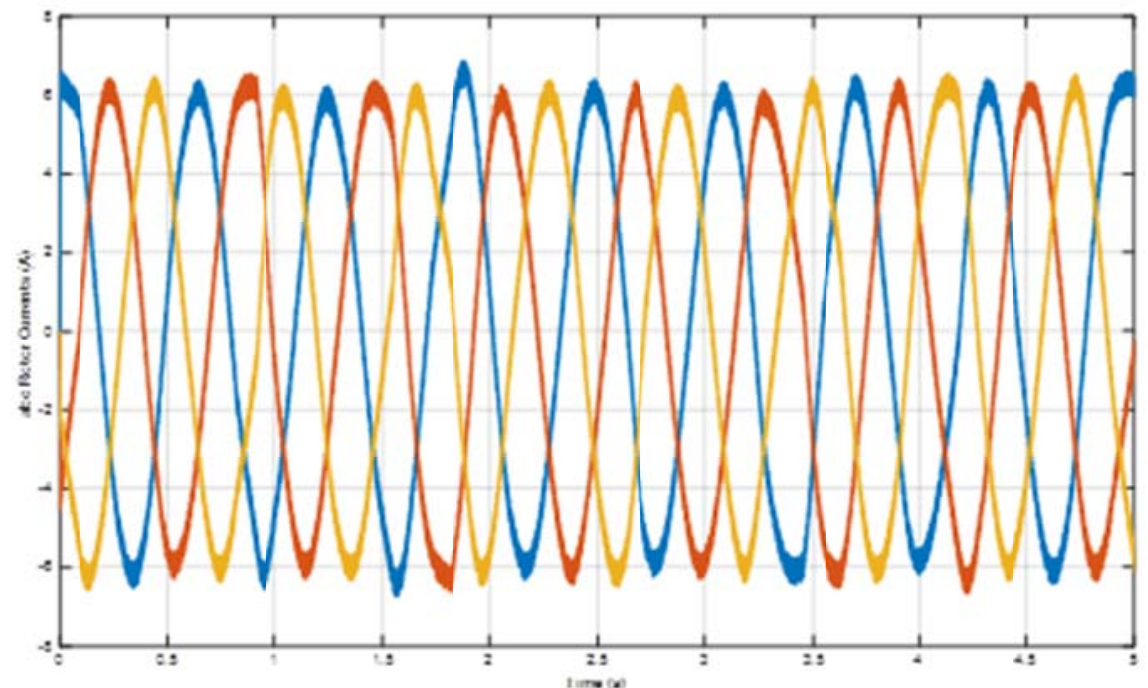

(d)

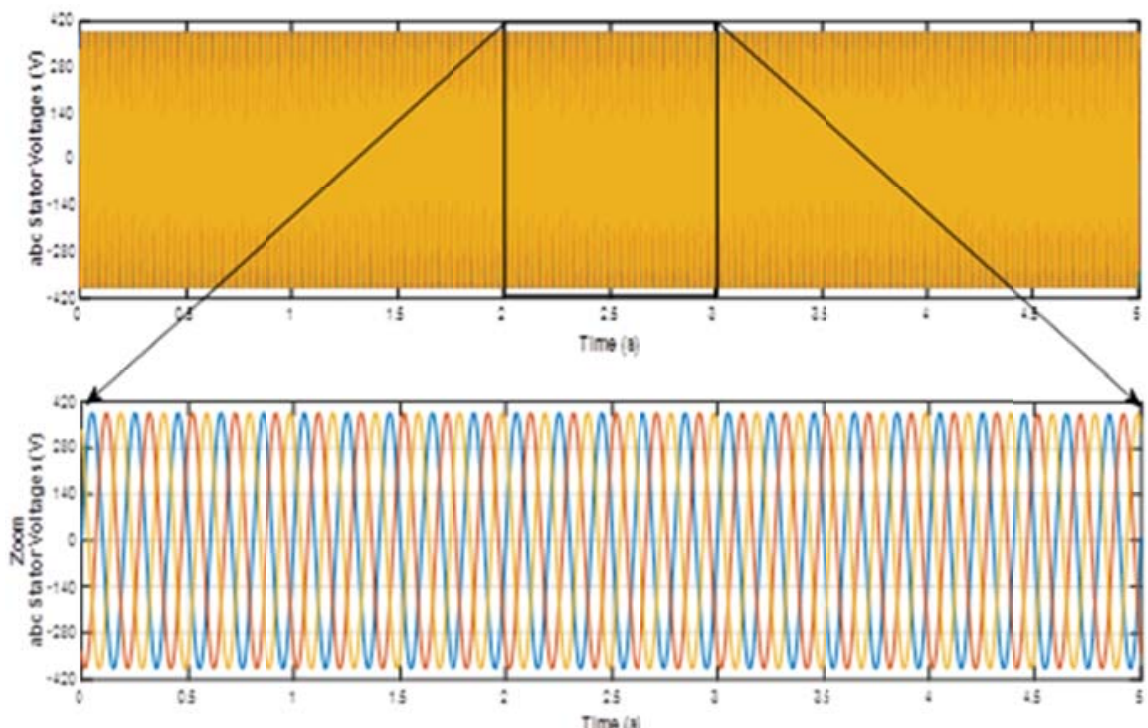

(e)

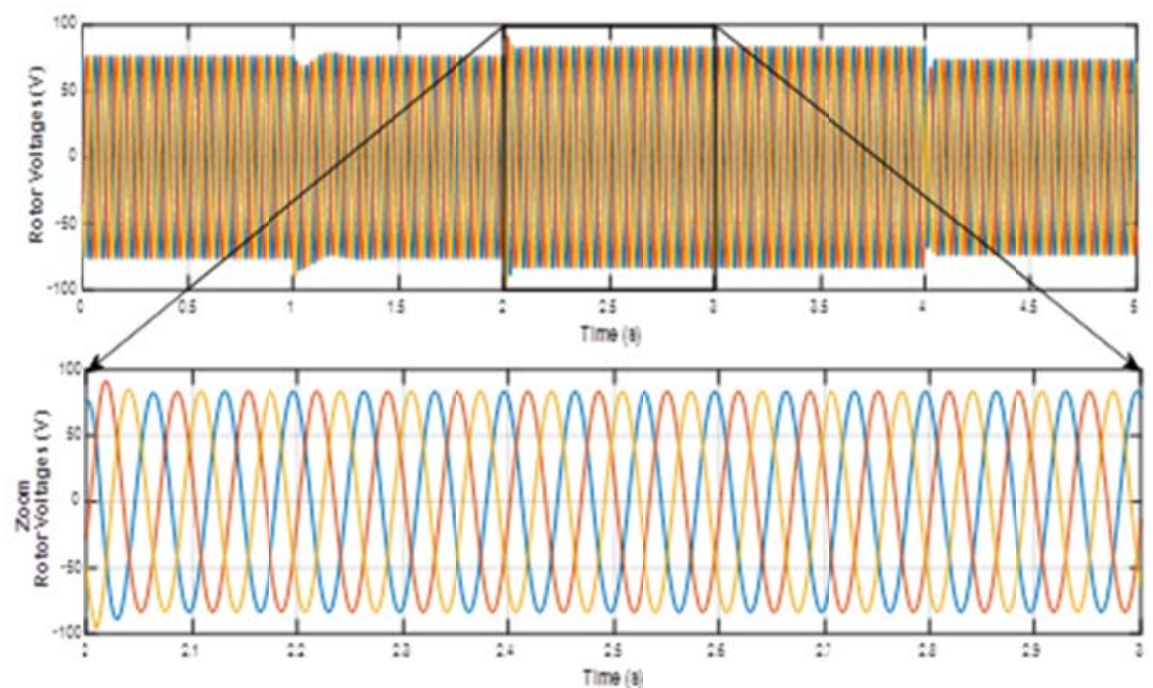

(f)

Figure 5. Curves of: (d) the currents of the rotor, (e) the voltages of the stator, (f) the voltages of the rotor 


\section{CONCLUSION}

This work proposes an improvement of the classical DPC control applied to the doubly fed induction generator (DFIG) integrated in a wind energy conversion system 'WECS'. The whole system is modeled and simulated in the environment Matlab/Simulink. Also, a technique (TSR) to reach the maximum power point (MPP) is presented in order to capture the maximum of power. The results (setpoint tracking and robustness test) in steady and transient regimes show a complete correlation. They both prove the robustness and efficiency of the method developed. In general, the simulation's results obtained during the application of the control under variable speed show an excellent dynamic performance and tracking ability of the powers generated at the corresponding reference values with the preservation of sinusoidal shapes for both currents and voltages (stator and rotor).

\section{REFERENCES}

[1] M. Bouderbala, B. Bossoufi, A. Lagrioui, M. Taoussi, Y. Ihedrane, H. Alami Aroussi, "Direct and Indirect Vector Control of a Douby Fed Induction Generator based in a Wind Energy Conversion System," in International Journal of Electrical and Computer Engineering (IJECE), vol. 9, no. 3, pp. 1531-1540, 2019.

[2] B. Bossoufi, M. Karim, A. Lagrioui, M. Taoussi, "FPGA-Based Implementation nonlinear Backstepping control of a PMSM Drive," International Journal of Power Electronics and Drive System (IJPEDS), vol. 4(1), pp. 12-23, 2014.

[3] Z. Chen, J. M. Guerrero and F. Blaabjerg, "A review of the state of the art of power electronics for wind turbines," IEEE Transactions on Power Electronics, vol. 24, no. 8, pp. 1859-1875, 2009.

[4] T. Ackermann, Wind power in power systems, John Wiley and Sons, Ltd, Londres, 2005.

[5] H. Alami Aroussi, el. M. Ziani, B. Bossoufi, "Contribution to the enhancement of dual DTC Application: Doubly fed induction motor," International Conference On Advanced Technologies For Signal\& Image Processing ATSIP'2017, May 2017

[6] B. Bossoufi, S. Ionita, H. Alami Aroussi, M. El Ghamrasni, Y. Ihedrane, "Managing voltage drops a variable speed wind turbine connected to the grid," in International Journal of Automation and Control, vol. 1(1), pp. 15-34, 2017.

[7] H. Alami Aroussi, El. M. Ziani, B. Bossoufi, "Speed Control Of The Doubly Fed Induction Generator Applied To A Wind System," in Journal Of Theoretical And Applied Information Technology, vol. 83, no. 3, pp. 426-433, 2016.

[8] S. Heier, Grid Integration of Wind Energy Conversion Systems, Publications John Wiley \& Sons, 1998.

[9] Lalouni S, Rekioua Djamila, Idjdarene, Kassa and Tounzi Abdelmounaim, "An improved MPPT algorithm for wind energy conversion system," J. Electr. Syst., vol. 10, pp. 484-494, 2014.

[10] S. Muller, M. Deicke, R. W. De Doncker, "Doudly Fed Induction Genertor Systems for Wind Turbines," IEEE Industry Applications Magazine, 2003.

[11] J. P. Caron, J. Hautier, Modélisation et commande de la machine asynchrone, Edition Technip, 1995.

[12] F. Mei, B. Pal, "Modelling and small-signal analysis of a grid connected doubly-fed induction generator," Power Engineering Society General Meeting, vol. 3, no. 1, pp. 2101-2108, 2005.

[13] S. Li, S. Sinha, "A Simulation Analysis of Double-Fed Induction Generator for Wind Energy Conversion Using Pspice," Power Engineering Society General Meeting, IEEE, 2006.

[14] B. Babypria, R. Anita, "Modelling, Simulation and Analysis of Doubly Fed Induction Generator for Wind Turbines," Journal of Electrical Engineering, vol. 60, no. 2, pp. 79-85, 2009.

[15] T. Noguchi, H. Tomiki, S. Kondo, and I. Takahashi, "Direct power control of PWM converter without power source voltage sensors," IEEE Industry Applications Conference, Thirty-First IAS Annual Meeting, IAS '96, vol. 2, pp. 941-946, 1996.

[16] Y. Djeriri, A. Meroufel, B. Belabbes and A. Massoum, "Three-level NPC voltage source converter based direct power control of the doubly fed induction generator at low constant switching frequency," Revue des Energies Renouvelables, Centre de Développement des Energies Renouvelables- CDER, Algérie, vol. 16, no. 1, pp. 91-103, 2013.

[17] Y. A Chapuis, "Contrôle Directe du Couple d'une Machine Asynchrone par L'orientation de son Flux Statorique," Thèse Doctorat INPG, génie électrique.

[18] Nik Rumzi Nik Idris, and Abdul Halim Mohamed Yatim, "Direct Torque Control of Induction Machines with Constant Switching Frequency and Reduced Torque Ripple," IEEE Transactions on Industrial Electronics, vol. 51, no. 4, 2004.

[19] Rachid, D; Othman, H.; Faouzi, B., "A Completely Vectored Direct Torque Control Scheme for Induction Motor," Systems, Man and Cybernetics, IEEE International Conference, vol. 5, 2002.

[20] Buja, G.; Casadei, D.; Serra, G., "Direct torque control of induction motor drives," Proceedings of The IEEE International Symposium, vol. 1, 1997.

[21] J. Lopez, E. Gubia, P. Sanchis, X. Roboam, L. Marroyo, "Wind turbines based on doubly fed induction generator under asymmetrical voltage dips", IEEE Trans. Energy Convers., vol. 23, no. 1, pp. 321-330, Mar. 2008.

[22] L. Xu, "Coordinated control of DFIG's rotor and grid side converters during network unbalance", IEEE Trans. Power Electron., vol. 23, no. 3, pp. 1041-1049, May 2008.

[23] Dawei Zhi, Lie Xu. "Direct Power Control of DFIG With Constant Switching Frequency and Improved Transient Performance," IEEE Trans. on Energy Conversion, 22(1):110-118, 2007. 
[24] Shanzhi Li, Haoping Wang, Yang Tian, Abdel Aitouch, John Klein, "Direct power control of DFIG wind turbine systems based on an intelligent proportional-integral sliding mode control", ISA Transactions, Volume 64, pp 431-439, 2016.

[25] G. Abad, M. A. Rodrguez, J. Poza, "Two level VSC based predictive direct torque control of the doubly fed induction machine with reduced torque and flux ripples at low constant switching frequency", IEEE Trans. Power Electron., vol. 23, no. 3, pp. 1050-1061, May 2008

\section{BIOGRAPHIES OF AUTHORS}
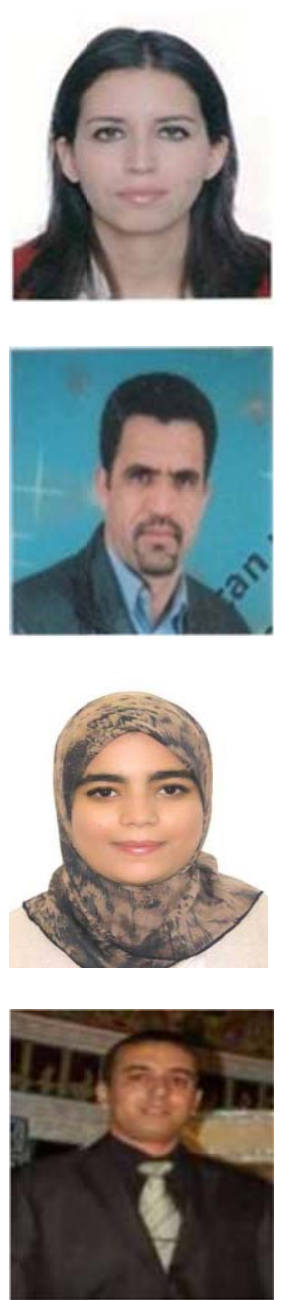

Hala Alami Aroussi received her M.S degree in Industrial Automated Systems Engineering from Sidi Mohammed Ben Abdellah University, Fez, Morocco. She is currently pursuing her Ph. D in Electrical Engineering at Mohamed Premier University, Oujda, Morocco. She is a member of the laboratory of electrical engineering and maintenance (LGEM). Her research interests include modeling, control of wind energy conversion systems using a doubly fed induction machine and renewable energy.

Elmostafa Ziani received his $\mathrm{PhD}$ in Electrical Engineering from Abdelmalek Essaadi University, Tangier, Morocco. Currently, he is the director of the Applied Engineering Department of the Ecole Supérieur de Technologie-Oujda and a member of the laboratory of electrical engineering and maintenance. He is author of several articles dealing with the application of intelligent instrumentation to the monitoring of complex systems, industrial systems and the contribution to the control and optimization of electrical conversion systems "wind and photovoltaic".His research interests include electrical engineering, power electronics and automation.

Bouderbala Manale is a Ph.D. Student in Electrical Engineering from the Faculty of Sciences Dhar El Mahraz, Sidi Mohammed Ben Abdellah University, Fez - Morocco. She is member of LISTA Laboratory. She had her master's degree in Engineering of Industrial Automated Systems at the Faculty of Sciences Dhar el Mahrez Fez. Her research interests include Renewable Energy, static converters, electrical motor drives, and power electronics.

Badre Bossoufi was born in Fez city, Morocco, on May 21, 1985. He received the Ph.D. degree in Electrical Engineering from University Sidi Mohammed Ben Abdellah, Faculty of Sciences, Morocco and PhD. degree from University of Pitesti, Faculty of Electronics and Computer, Romanie and Montefiore Institute of electrical engineering, Luik, Belgium, in 2013. He is a Professor of Electrical Engineering, at the LISTA Laboratory Faculty of Sciences Dhar El Mahraz, Sidi Mohammed Ben Abdellah University, Fez - Morocco. His research interests include static converters, electrical motor drives, power electronics, Smart Grid, Renewable Energy and Artificial Intelligent. 